\title{
Different non-synonymous polymorphisms modulate the interaction of the WRN protein to its protein partners and its enzymatic activities
}

\author{
Jean-Philippe Gagné ${ }^{1}$, Sophie Lachapelle ${ }^{2}$, Chantal Garand ${ }^{1}$, Serges P. Tsofack ${ }^{1}$, \\ Yan Coulombe ${ }^{2}$, Marie-Christine Caron ${ }^{2}$, Guy G. Poirier ${ }^{1}$, Jean-Yves Masson ${ }^{2}$ and \\ Michel Lebel ${ }^{1}$ \\ ${ }^{1}$ Centre de Recherche du CHU de Québec, Pavillon CHUL Université Laval, Faculté de Médecine, Québec, Canada \\ ${ }^{2}$ Centre de Recherche sur le Cancer de I'Université Laval, Hôpital Hôtel-Dieu de Québec, Québec, Québec, Canada \\ Correspondence to: Michel Lebel, email: michel.lebel@crchudequebec.ulaval.ca \\ Keywords: mass spectrometry, proteomics, werner syndrome, polymorphism, exonuclease, Gerotarget \\ Received: October 30, $2015 \quad$ Accepted: September 27, $2016 \quad$ Published: November 14, 2016
}

\section{ABSTRACT}

Werner syndrome (WS) is characterized by the premature onset of several ageassociated pathologies including cancer. The protein defective in WS patients (WRN) is a helicase/exonuclease involved in DNA replication and repair. Here, we present the results of a large-scale proteome analysis that has been undertaken to determine protein partners of different polymorphic WRN proteins found with relatively high prevalence in the human population. We expressed different fluorescently taggedWRN (eYFP-WRN) variants in human 293 embryonic kidney cells (HEK293) and used a combination of affinity-purification and mass spectrometry to identify different compositions of WRN-associated protein complexes. We found that a WRN variant containing a phenylalanine residue at position 1074 and an arginine at position 1367 (eYFP-WRN(F-R)) possesses more affinity for DNA-PKc, KU86, KU70, and PARP1 than a variant containing a leucine at position 1074 and a cysteine at position 1367 (eYFP-WRN(L-C)). Such results were confirmed in a WRN-deficient background using WS fibroblasts. Interestingly, the exonuclase activity of WRN recovered from immunoprecipitated eYFP-WRN(L-C) variant was lower than the eYFP-WRN(F-R) in WS cells. Finally, HEK293 cells and WS fibroblasts overexpressing the eYFP-WRN(F-R) variant were more resistant to the benzene metabolite hydroquinone than cells expressing the eYFP-WRN(L-C) variant. These results indicate that the protein-protein interaction landscape of WRN is subject to modulation by polymorphic amino acids, a characteristic associated with distinctive cell survival outcome.

\section{INTRODUCTION}

Werner Syndrome (WS; MIM number \#277700) is a rare autosomal recessive disorder that displays many of the clinical symptoms of aging at an early age. From their second decade of life onward, WS patients develop pathologies that prematurely resemble many traits of normal aging such as osteoporosis, ocular cataracts, graying and loss of hair, diabetes mellitus, arteriosclerosis, and cancer [1-4]. Death generally occurs in the fifth decade of life from heart demise or cancer. Accumulating evidences indicate that the WRN (MIM number 604611) encoded gene product is a suppressor of illegitimate DNA recombination. Indeed, WS cells are characterized by the presence of deletions and variegated chromosomal translocations $[5,6]$. Processes such as DNA replication or transcription generate regions of single-stranded DNA, which may inadvertently provide a substrate for the initiation of recombination. Various mechanisms have evolved to ensure that recombination does not occur promiscuously during these processes and the WRN protein may be part of one such mechanism. Thus, one potential role for WRN would be to actually monitor recombinational repair of double-strand breaks [7]. During the process of recombination, nonhomologous regions of DNA could inadvertently be used as templates for repair. WRN protein will not inhibit the initiation of recombination but will dissociate abnormal recombination 
intermediates [8-10]. Accordingly, purified WRN protein has an affinity for DNA fork structures such as those observed during DNA recombination [11]. Furthermore, WRN can migrate Holliday junctions (a recombination intermediate) [8]. Thus, a mutation in WRN may lead to an increased frequency of illegitimate recombination during the repair of breaks at transcriptional sites or DNA replication forks, creating small deletions or variegated chromosomal translocations. In addition to homologous recombination, WRN is involved with the KU70/86 complex and DNA-PKc in nonhomologous end joining reactions $[12,13]$. Finally, the interplay between poly(ADP-ribose) polymerase 1 (PARP1) and WRN plays an essential role in maintaining genome integrity in eukaryotic cells [14, 15], notably by suppressing oxidized DNA in long patch base excision pathway [16, 17]. Thus, WRN is likely to be involved in multiple DNA repair pathways. In the absence of a functional WRN protein, accumulation of deletions and translocations could potentially inactivate tumor suppressor genes or activate oncogenes, accelerating tumor formation and/ or aggressiveness. The most frequent cancers in WS patients are thyroid neoplasms, malignant melanoma, meningioma, soft tissue sarcomas, leukemia and preleukemic conditions of the bone marrow [18].

Despite the rarity of WS, several common polymorphisms in the $W R N$ gene have been associated with different cancers in specific populations. The two most common polymorphisms (most common in the general population) that have been analyzed are single nucleotide polymorphisms (SNPs) that substitute amino acid 1074 (Leu to Phe) or amino acid 1367 (Cys to Arg) of the WRN coding sequence. If we consider the helicase domain as being in the middle of the WRN protein sequence, each of these changes are located $\mathrm{C}$-terminal to the DNA helicase catalytic domain (Figure 1A). It has been reported that the Arg allele at position 1367 of the $W R N$ gene product is protective against bone and soft tissue sarcomas in Japan [19]. Similarly, the same Arg allele was associated with a lower risk of non-Hodgkin lymphoma among women in the state of Connecticut in the USA [20]. Although some studies suggested the lack of correlation between the Arg1367 allele and the development of non-Hodgkin lymphoma [21, 22], a metaanalysis of several genome-wide association studies has rather indicated a relationship between the Arg1367 allele and the incidence of this lymphoma [23].

Several other studies have indicated an association between the Arg1367 allele of the WRN gene product and different cancer types. For example, the Arg/Arg genotype was associated with higher mean age of onset of gastric cancer in Brazil and a higher risk of esophageal cancer in China [24, 25]. In two studies, one Arg1367 allele was sufficient to increase the risk of developing breast cancer among German and American women [26, 27]. In contrast, Chinese women with a Phe/Phe genotype at position
1074 of the WRN protein showed an increased risk of developing breast cancer but no association was found between the Arg1367 variant and breast cancer in the same population [28]. Finally, the Phe/Phe genotype at position 1074 of the WRN protein is associated with increased risk of lung cancer in the UK [29] and Chinese subjects with one Leu1074 variant is associated with a lower prevalence of prostate cancer [30]. The contradictory results between these reports may be due to the different sample size under study. Furthermore, population stratification and ethnic considerations influence the interpretation of the association results.

Interestingly, haplotypic analyses on different $W R N$ coding SNPs indicated that Chinese workers exposed to benzene were more at risk of developing hematotoxicity depending on their polymorphisms [31, 32]. It was concluded that the combination of different SNPs at both amino acid positions 1074 and 1367 of the WRN protein had broad effects on the count of several white blood cell subtypes upon benzene-induced hematotoxicity. This latter work is an example of the few reports analyzing SNP combinations of the $W R N$ gene in association studies.

The exact cellular impact of these polymorphisms in the $W R N$ gene and how they contribute to chemical toxicity and cancer predisposition remains rudimentary. Although the WRN Cys1367Arg substitution is located close to the nuclear localization signal motif, no difference in nuclear localization could be detected between the Cys1367 and the Arg1367 WRN variants [33]. Furthermore, no significant difference could be detected between the Arg1367 and the Cys1367 purified WRN variants or the Leu1074 and the Phe1074 variants with regards to in vitro exonuclease or helicase activities [34]. One possibility is that these variants may affect the interaction of the $W R N$ gene product with other nuclear proteins. In this study, we show for the first time that different polymorphic WRN protein variants have distinct macromolecular protein complexes composition as a consequence of altered physical affinity for various DNA damage response factors. Such changes in the local environment of WRN may directly modulate its activity towards alternate or damaged DNA structures.

\section{RESULTS}

\section{Identification of WRN-interacting proteins by mass spectrometry}

To identify multi-protein complexes specifically associated with different WRN polymorphic variants, we transfected human 293 embryonic kidney cells with eYFPWRN expression constructs containing the Leu1074Cys1367, Phe1074-Cys1367, Leu1074-Arg1367, or Phe1074-Arg1367 variant. The numbers represent the 
Table 1: List of nuclear proteins identified by mass spectrometry interacting with all the different WRN variants

\begin{tabular}{|l|l|l|l|l|l|}
\hline \multirow{2}{*}{ Gene name } & \multicolumn{4}{|l|}{ Number of unique peptides } & \multirow{2}{*}{ Description } \\
\cline { 2 - 5 } & FC* & FR & LC & LR & \\
\hline PRKDC & 172 & 470 & 20 & 216 & DNA-dependent protein kinase catalytic subunit \\
\hline WRN & 163 & 198 & 176 & 130 & Werner syndrome gene product \\
\hline TMPO & 60 & 172 & 51 & 13 & Thymopentin (lamina-associated polypeptide 2) \\
\hline XRCC5 & 35 & 148 & 17 & 29 & KU86 ATP-dependent DNA helicase 2 subunit 2 \\
\hline XRCC6 & 41 & 89 & 22 & 48 & KU70 ATP-dependent DNA helicase 2 subunit 1 \\
\hline RPA1 & 22 & 40 & 43 & 21 & Replication protein A 70 kDa DNA-binding subunit \\
\hline PARP1 & 10 & 23 & 9 & 8 & Poly(ADP-ribose) polymerase 1 \\
\hline RPA2 & 6 & 19 & 11 & 9 & Replication protein A 32 kDa subunit \\
\hline CUX1 & 8 & 5 & 9 & 9 & Homeobox protein cut-like 1 \\
\hline LIG3 & 5 & 10 & 3 & 2 & DNA ligase 3 \\
\hline HNRNPA2B1 & 6 & 3 & 10 & 2 & Heterogeneous nuclear ribonucleoprotein A2/B1 \\
\hline HERC2 & 3 & 8 & 5 & 7 & Hect domain-containing protein 2-E3 ubiquitin ligase \\
\hline CHD4 & 6 & 4 & 7 & 6 & Chromodomain-helicase-DNA-binding protein 4 \\
\hline HSPD1 & 3 & 7 & 7 & 2 & 60 kDa heat shock protein \\
\hline HIST1H4A & 2 & 5 & 6 & 2 & Histone H4 \\
\hline VRK3 & 5 & 5 & 6 & 4 & Vaccinia related kinase 3 \\
\hline SATB2 & 2 & 4 & 2 & 3 & DNA-binding protein SATB2 \\
\hline
\end{tabular}

*FC corresponds to YFP-WRN with F amino acid at position 1074 and $\mathrm{C}$ at position 1367, FR corresponds to YFP-WRN with $\mathrm{F}$ at position 1074 and $\mathrm{R}$ at position 1367, LC corresponds to YFP-WRN with L at position 1074 and $\mathrm{C}$ at position 1367 , LR corresponds to YFP-WRN with $\mathrm{L}$ at position 1074 and $\mathrm{R}$ at position 1367 . $\mathrm{F}=$ phenylalanine, $\mathrm{L}=\mathrm{leucine}, \mathrm{C}=\mathrm{cysteine}$, $\mathrm{R}=\operatorname{arginine}$.

position of the indicated amino acids in the different WRN protein variants (Figure 1A). There are many advantages to the use of eYFP-WRN chimera in our proteomewide analysis. The YFP-tag confers a strong affinity to commercially available antibodies against eYFP for largescale immunoprecipitation experiments. N-terminal eYFP tagging of WRN have minimal effect on its sub-cellular localization, tertiary structure or biological activity, and thus recapitulates the dynamics of the endogenous WRN protein. In addition, the overexpression of eYFP-WRN to facilitate its isolation in whole-cell extracts is a very effective strategy that has previously been performed to identify WRN-interacting proteins [35].

For the affinity-purification of WRN-associated protein complexes, immunoprecipitation assays were carried out under rather mild detergent and ionic strength that allowed efficient isolation of intact protein complexes (see Materials and Methods). Broad specificity DNAse and RNAses were added in the extraction buffer to favor the identification of direct protein-protein interactions and to minimize protein/nucleic acid/WRN interactions. The immunoprecipitated proteins were resolved by SDSPAGE and stained with Sypro Ruby (Figure 1B). The entire protein eluate resolved by SDS-PAGE was extracted for a complete coverage of the co-immunoprecipitated proteins rather than limited to high-abundance protein bands. Protein tracks were cut into several slices for ingel trypsin digestion followed by liquid chromatography tandem mass spectrometry (LC-MS/MS). Using stringent protein identification criteria, we could reliably annotate a total of $7677 \mathrm{MS} / \mathrm{MS}$ spectra corresponding to 442 unique proteins (data available upon request). Common unspecific proteins (keratins, serum albumin, trypsin, IgGs) and unspecific binding proteins found in control eYFP immunoprecipitation extracts were cut out of the dataset to generate a preliminary listing of 375 potential WRN-interacting proteins (Supplementary Table S1). Since WRN is exclusively a nuclear protein, we finally restricted the remaining of our study to a list containing exclusively nuclear proteins or proteins known to shuttle to the nucleus. Based on gene ontology terms "nucleus" and "DNA metabolic process" (using DAVID), the supplementary Table S1 also indicates 183 nuclear proteins co-immunoprecipitating with the different eYFPWRN construct variants. Table 1 gives a list of nuclear proteins co-immunoprecipitated with the different eYFPWRN construct variants with a minimum of two unique peptides assignments. Proteins such as DNA-PKc, TMPO, KU86, KU70, RPA1, PARP1, and RPA2 were among the proteins identified with the highest peptide spectral counts, a parameter that can be used as a semi-quantitative readout of relative protein abundance.

One striking observation regarding WRN-interacting proteins is the massive variations of spectral counts relative to the KU70/KU86/DNA-PKc complex involved in the nonhomologous end joining DNA repair pathway (Table 1). The index of spectra assigned to DNA-PKc, KU86, and KU70 correlates with the intensities of the bands shown in the Sypro Ruby staining (arrows in Figure 1B and relative abundance in Figure 1C). To confirm the 


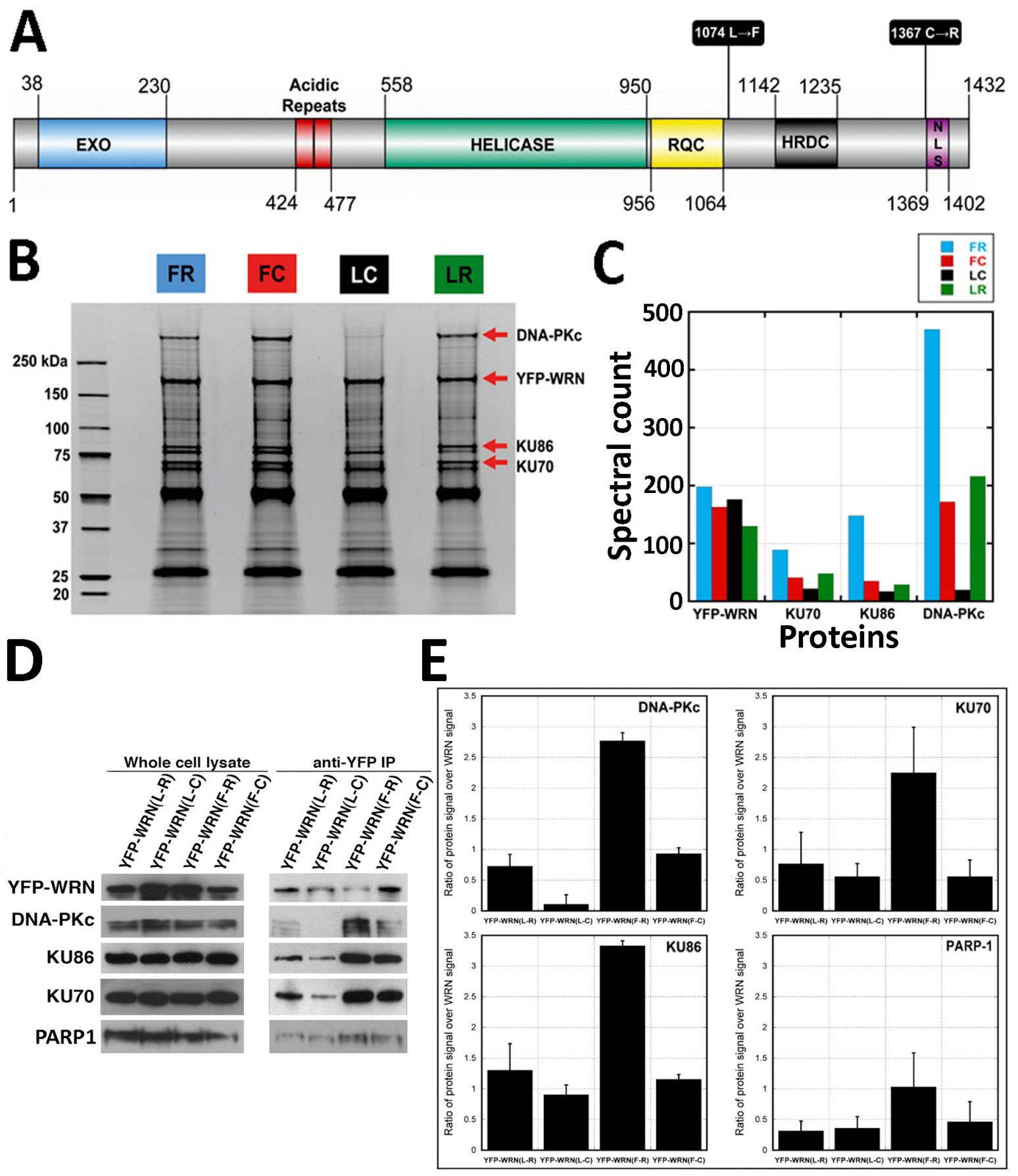

Figure 1: Co-purification of WRN-interacting proteins. Affinity-purification of eYFP-tagged WRN variants was performed with antibody-coupled magnetic beads in HEK293 whole cell extracts. A. Schematic representation of the human WRN protein with the different polymorphic residues targeted in this study. $\mathrm{C}=$ cysteine; $\mathrm{F}=$ phenylalanine; $\mathrm{L}=$ leucine; $\mathrm{R}=$ arginine. Domain boundaries were drawn according to Uniprot (UniProtKB - Q14191) and [56]. B. Protein profiles of WRN-interacting proteins. Immunoprecipitation extracts obtained with each eYFP-WRN variants were resolved on SDS-PAGE and stained with SYPRO. All immunoprecipitations were performed $24 \mathrm{~h}$ after the transfection of eYFP-WRN expressing vectors. Molecular-mass sizes are indicated in kilodaltons (kDa). Arrows point to bands identified as major eYFP-WRN variants: DNA-PKc, KU86, and KU70 proteins. C. Diagram showing a summary of the spectral counts for YFP-WRN, DNA-PKc, KU86, and KU70 proteins from the tandem mass spectrometry analysis of protein extracts shown in B.. D. Selected WRN-interacting proteins found by mass spectrometry analysis in eYFP-WRN immunoprecipitation extracts (anti-YFP IP) from transfected HEK293 cells were validated by Western blot analysis. A representative Western blot is shown with antibodies against DNA-PKc, KU86, KU70, and PARP1. E. Semi-quantitative analysis of protein abundance in eYFP-WRN immunoprecipitation extracts. The enrichment ratios of the indicated co-immunoprecipitated protein signal over the immunoprecipitated eYFP-WRN signal are indicated in the histograms. All co-immunoprecipitation analyses were performed in duplicate. Error bars (standard error of the mean (SEM)) are indicated for each histogram. 
differential interactions between DNA-PKc, KU86, or KU70 and the different eYFP-WRN variants, HEK 293 cells were first transfected with the different eYFP-WRN expression vectors followed by immunoprecipitation of the eYFP-WRN variants 24 hours later with the antieYFP antibody. The immunoprecipitates were analyzed by Western blotting with the appropriate antibodies. As shown in Figure 1D, DNA-PKc was hardly detectable in the immunoprecipitate of the eYFP-WRN(L-C) variant compared to the other three variants (Figure 1D and 1E). It was detected only after a long exposure (45 min) of the immunoblot (supplementary Figure S1A). In contrast, the eYFP-WRN(F-R) is much more proficient to pulldown DNA-PKc and its regulatory KU subunits. More KU86 protein was recovered from the eYFP-WRN(F-R) immunoprecipitation experiments than the other variants (Figure 1D and 1E). The eYFP-WRN(F-R) variant also co-immunoprecipitated more KU70 than the other variants (Figure 1D and 1E).

Since PARP1 was also one of the major DNA repair protein bound to WRN (Table 1), we also examined the amount of PARP1 co-immunoprecipitated with the different variants. As indicated in Figures $1 \mathrm{D}$ and $1 \mathrm{E}$, the eYFP-WRN(F-R) variant co-immunoprecipitated more PARP1 than the other variants. These results are consistent with spectra count-based estimates of the LCMS/MS analysis (Table 1). Together, these results indicate that different polymorphic amino acids in WRN affect its affinity to DNA-PKc, PARP1 and the KU complex, which are major components of DNA damage response.
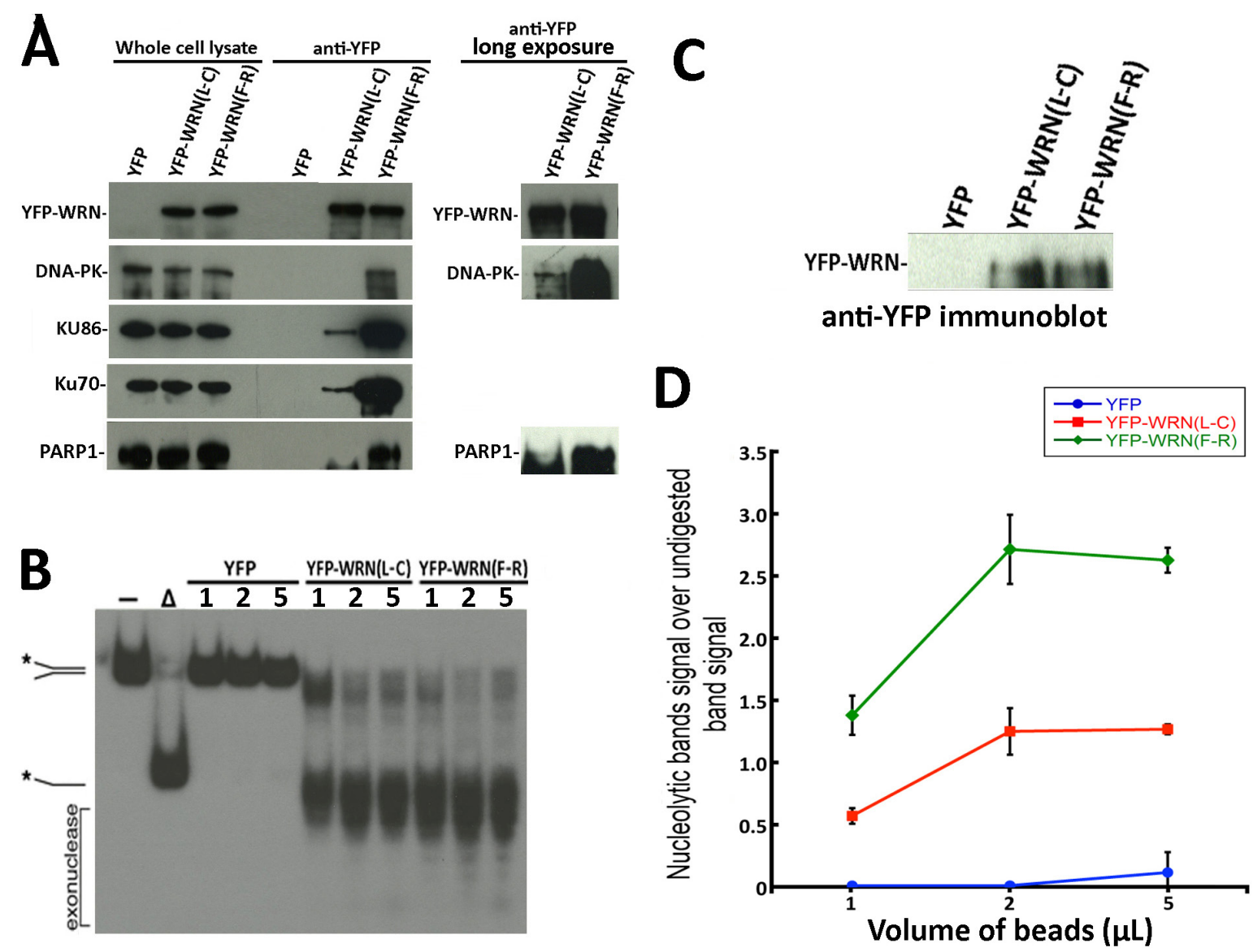

Figure 2: Immunoprecipitation of eYFP-WRN variants in WS fibroblasts (AG11395B) and evaluation of WRN exonluclease activity. A. Representative Western blots against selected WRN-interacting proteins in WRN immunoprecipitation extracts from WS fibroblasts transfected with the eYFP-WRN(L-C) and eYFP-WRN(F-R) variants. Longer exposures of the immunoblots are shown on the right for DNA-PKc and PARP1. B. Evaluation of the exonuclease activity in eYFP (control), eYFP-WRN(L-C) and eYFP-WRN(F-R) immunoprecipitation extracts. The volumes of magnetic beads containing the eYFP-WRN variants and their interacting proteins were added as indicated for the enzymatic reactions. A radiolabeled splayed arms DNA was used as a WRN substrate to evaluate its exonuclease activity. The position of the different DNA processed forms and the nuclease fragments are indicated on the left. The autoradiogram shown represents $18 \mathrm{~h}$ of exposition. The asterisk indicates the radioactive strand. C. Western blot showing the levels of eYFP-WRN variants in transfected WS fibroblasts that were used for the enzymatic assays in B. D. Quantification of WRN exonuclease activity associated with eYFP-WRN(L-C) and eYFP-WRN(F-R) immunoprecipitation extracts. Activity ratios were calculated relative to the undigested band signal from the autoradiogram shown in B. The experiments were performed in duplicates. The error bars represent the SE. 


\section{Enzymatic activities of two eYFP-WRN polymorphic variants}

We next analyzed the enzymatic activities of two different immunoprecipitated eYFP-WRN variants on a radioactive forked structure that showed the greatest difference in binding to DNA-PKc, KU86, KU70, and PARP1. The eYFP-WRN(F-R) and eYFP-WRN(L-C) variants were transfected in WRN-deficient WS fibroblasts (AG11395B). The eYFP expression vector was used as a control. The immunoprecipitations were performed as described in the preceding section except that Benzonase ${ }^{\mathbb{B}}$ and RNAse A were excluded from the lysis buffer to avoid contamination with these nucleases in the final step of our in vitro enzymatic assays. First, we reconfirmed the differential co-immunoprecipitation of DNA-PKc, KU86, KU70, and PARP1 on the eYFP-WRN(F-R) and eYFP-WRN(L-C) variants in WS fibroblasts (Figure 2A). As seen with the HEK293 cells, more DNA-PKc, KU86, KU70, and PARP1 were co-immunoprecipitated from the WS fibroblasts with the eYFP-WRN(F-R) variant than the eYFP-WRN(L-C) variant. Furthermore, we had to expose the immunoblots for a longer time to detect DNA-PKc and PARP1 in the eYFP-WRN(L-C) immunoprecipitates (Figure 2A). The amount of immunoprecipitated eYFPWRN protein was evaluated by Western blotting for each variant to perform the in vitro enzymatic reactions with similar amounts of eYFP-WRN protein (Figure 2C). The enzymatic activities of the eYFP-WRN(F-R) variant were more efficient than the activity of the eYFPWRN(L-C) variant (Figure 2B). The experiments were performed twice and the average enzymatic activity was approximately 1.5 -fold higher with the eYFP-WRN(F-R) variant compared to the eYFP-WRN(L-C) (Figure 2D). Very little exonuclease and helicase activities were detected in the eYFP immunoprecipitate (Figure 2D). These results indicate that not only the immunoprecipitates of different eYFP-WRN variants tested contained different amount of DNA repair partner proteins but also exhibited different enzymatic activities in vitro toward a forked DNA structure.

\section{Cellular sensitivity to DNA damaging agents in the context of eYFP-WRN polymorphic variants}

It has been reported that Chinese workers exposed to benzene exhibited different level of hematotoxicity depending on specific SNPs in the WRN gene [32]. We first determined the impact of the benzene metabolite hydroquinone on cell survival in HEK293 cells expressing either eYFP-WRN (L-C) or (F-R) variants. We determined by fluorescence microscopy that the transfection efficiency of HEK293 cells was $>80 \%$ with Effectene reagents (Qiagen). Transfected cells were treated overnight with different concentrations of hydroquinone, fixed, and stained with sulforhodamine B. As indicated by the survival curves in Figure 3A, cells transfected with the eYFP-WRN(L-C) variant were $\sim 19 \%$ more sensitive to hydroquinone than the eYFP-WRN(F-R) transfected cells. The protein transfection levels of eYFP-WRN variants were similar from one transfection experiment to another (Figure 3B and 3C). The $\mathrm{IC}_{50}$ for the eYFP-WRN(F-R) and eYFP-WRN(L-C) variants were $50.2 \mu \mathrm{M}$ and 40.6 $\mu \mathrm{M}$, respectively (Figure 3D; $P$-value $=0.011$ ). Note that sequencing of the HEK293 exons encompassing the polymorphic amino acids under study revealed that such cells express an endogenous WRN with a Leu at position 1074 and a Cys at position 1367 (data not shown). Thus, overexpression of a polymorphic eYFP-WRN(L-C) protein in HEK293 cells had a negative effect on survival compared to cells overexpressing the eYFP-WRN(F-R) variant in an endogenous WRN(L-C) background.

To determine whether hydroquinone treatment could increase the interaction of the eYFP-WRN variants with DNA-PKc, KU86, KU70, and PARP1 proteins, immunoprecipitations were performed with extracts of hydroquinone-treated cells as well. As indicated in Figure 3E, more DNA-PKc, KU86, KU70, and PARP1 proteins were co-immunoprecipitated with the eYFP-WRN(F-R) variant than eYFP-WRN(L-C). (The supplementary Figure S1B presents a longer exposure to reveal the DNA-PKc protein in the eYFP-WRN(L-C) immunoprecipitate). The addition of hydroquinone, however, did not significantly change the amount of DNA-PKc, KU86, KU70, and PARP1 proteins co-immunoprecipitated with either eYFPWRN variant (Figure 3E).

Hydroquinone is a genotoxic compound suspected to act as a cancer-causing agent. To determine whether double-strand breaks could affect the survival of transfected HEK293 cells, we treated these cells with the radiomimetic DNA double-strand cleaving agent neocarzinostatin. The amount of eYFP-WRN variants expressed in all HEK293 transfected cells was similar based on Western blot analyses (Figure 3F). As indicated in Figure $3 \mathrm{G}$, no difference in resistance to neocarzinostatin could be detected between HEK293 cells transfected with the eYFP-WRN(L-C) or the eYFP-WRN(F-R) variant. Since hydroquinone can also induce an oxidative stress $[36,37]$, we examined the impact of hydrogen peroxide on transfected cells as well. As indicated in Figure $3 \mathrm{H}$, cells transfected with the eYFP-WRN(L-C) variant were $\sim 43 \%$ more sensitive to hydrogen peroxide than the eYFP-WRN(F-R) transfected cells. The $\mathrm{IC}_{50}$ for the eYFP-WRN(F-R) and eYFP-WRN(L-C) variants were $74.4 \mu \mathrm{M}$ and $42.3 \mu \mathrm{M}$, respectively. These results indicate that different polymorphic variants of the WRN protein influence how HEK293 cells respond to oxidative stress.

Since a WRN/PARP1 complex is required for cellular survival upon oxidative stress [16], we examined the contribution of PARP-1 activation to the altered hydroquinone sensitivity observed between eYFP- 

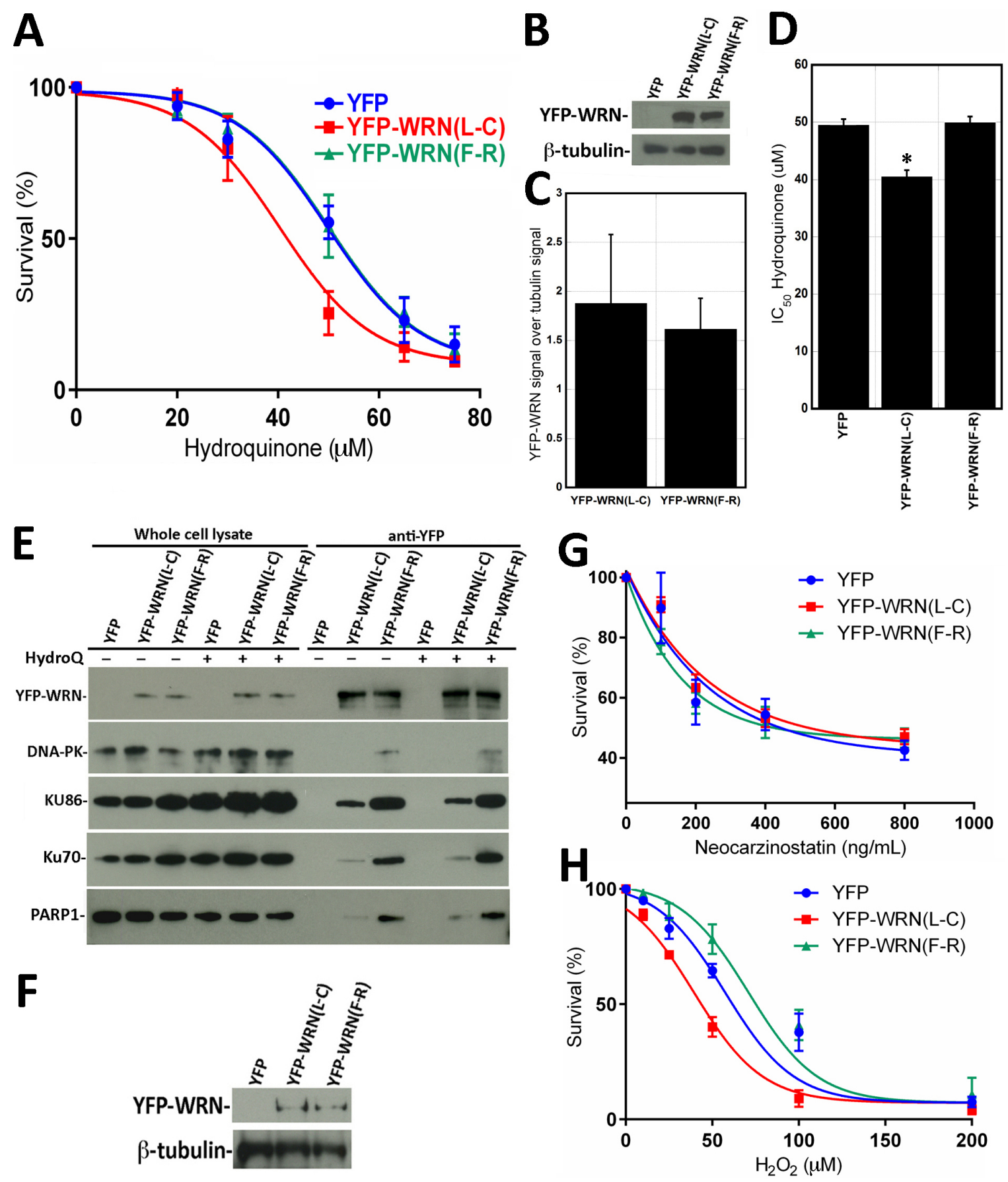

Figure 3: Dose-response curves of HEK293 cells expressing eYFP-WRN(L-C) and eYFP-WRN(F-R) variants exposed to genotoxic agents as determined by the sulforhodamine B colorimetric assay. A. Graph showing the hydroquinone sensitivity of HEK293 cells expressing the eYFP-WRN variants as determined by the sulforhodamine B colorimetric assay. Experiments were repeated four times. Bars represent SE. B. Representative Western blot showing the expression of the eYFP-WRN variants in transfected HEK293 cells. $\beta$-tubulin was used as a loading control. C. Histogram presenting the ratio of eYFP-WRN signal over $\beta$-tubulin signal from Western blots. Bars represent SE. D. Histogram representing the $\mathrm{IC}_{50}$ of HEK293 cells expressing the eYFP-WRN(L-C) and (F-R) variants exposed to hydroquinone. Bars represent SEM. (*Unpaired student $t$-test $P$-value $=0.028$ compared to the eYFP-WRN(F-R) variant). E. Representative Western blots against selected WRN-interacting proteins in WRN immunoprecipitation extracts in HEK293 cells treated with or without $40 \mu \mathrm{M}$ hydroquinone (HydroQ). F. Example of a representative Western blot showing the expression of the eYFP-WRN variants in transfected HEK293 cells exposed to neocarzinostatin. ß-tubulin was used as a loading control. G. Cell survival curve of HEK293 cells exposed to neocarzinostatin. H. Cell survival curve of HEK293 cells exposed to hydrogen peroxide $\left(\mathrm{H}_{2} \mathrm{O}_{2}\right)$. HEK293 cells were transfected with the indicated eYFP-WRN expressing vectors, exposed to the DNA damaging agents for 30 minutes with the indicated concentration range and allowed to recover for 48 hours in fresh media. The neocarzinostatin and hydrogen peroxide experiments were done in triplicates. Bars represent SE. 
WRN(L-C) and eYFP(F-R) expressing cells in additional survival assays. We thus treated the tranfected cells with the PARP1 inhibitor BMN-673 [38] for one hour prior to hydroquinone treatments (Figure 4A). The supplementary Figure S2 shows that the induction of poly(ADP)- ribosylation following hydroquinone-mediated DNA damage and PARP1 activation is totally inhibited by pretreatment of cells with BMN-673. As indicated in Figure 4, the PARP1 inhibitor sensitized all the transfected cells to the drug hydroquinone. The $\mathrm{IC}_{50}$ for the eYFP-
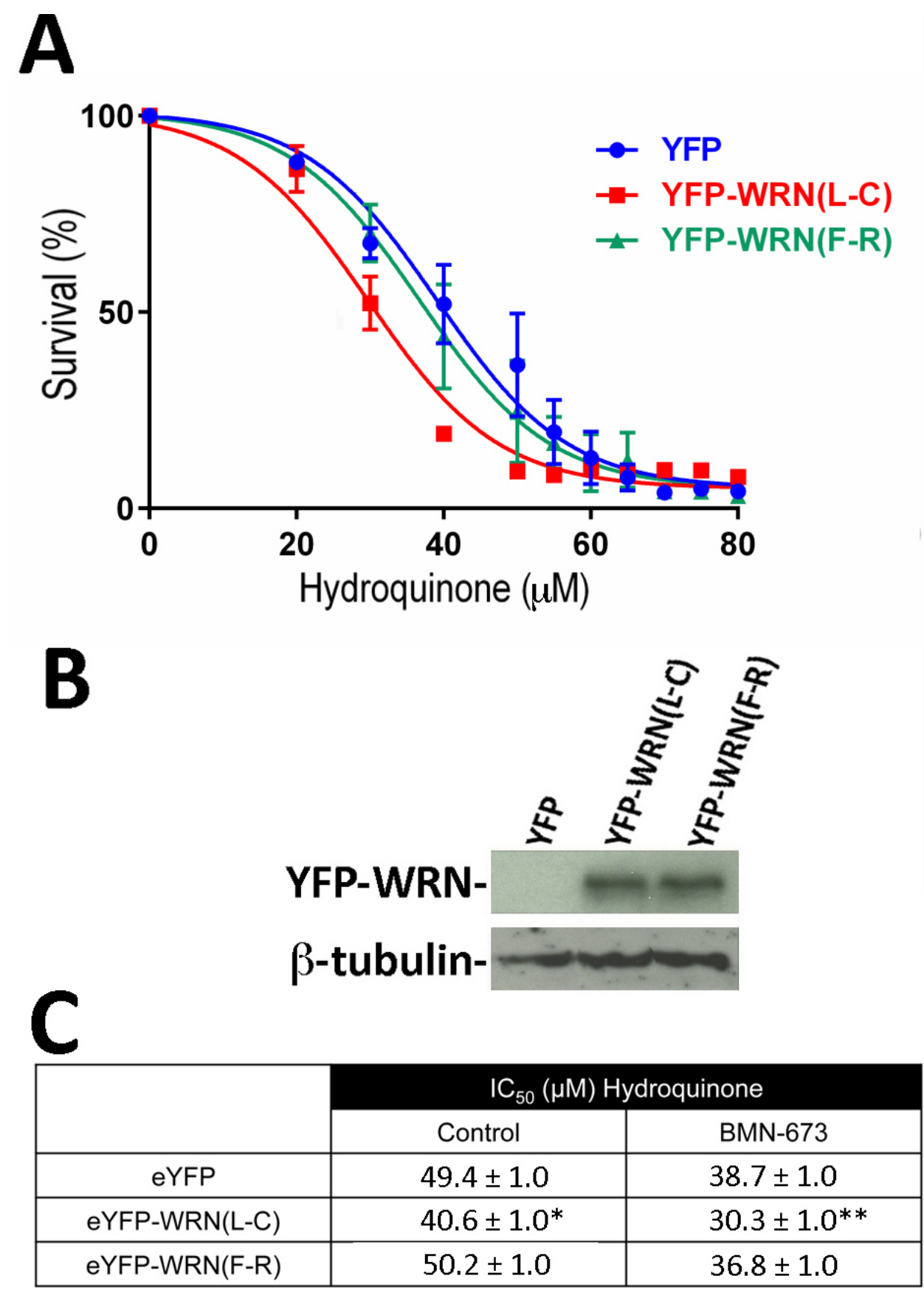

Figure 4: Dose-response curves of HEK293 cells expressing the eYFP-WRN(L-C) and eYFP-WRN(F-R) variants in presence of hydroquinone and PARP inhibition. A. Cells were transfected with the indicated eYFP-WRN variants encoding vectors. Following overnight transfection, cells were treated one hour with $1 \mu \mathrm{M}$ of the PARP1 inhibitor BMN-673 prior to exposure to increasing doses of hydroquinone for 24 hours. Hydroquinone dose-response curves were determined by the sulforhodamine B colorimetric assay. The experiments were performed in triplicates. Bars represent SE. B. Representative Western blot showing the expression of the eYFP-WRN variants in transfected cells. ß-tubulin was used as a loading control. C. Calculated $\mathrm{IC}_{50}( \pm$ SEM) of HEK293 cells expressing WRN variants from three different hydroquinone dose-response assays in the absence (control) or presence of the PARP1 inhibitor BMN673. $(* P$-value $=0.011$ and $* * P$-value $<0.001$ for eYFP-WRN(L-C) $v s$ eYFP-WRN(F-R)). 
WRN(F-R) and eYFP-WRN(L-C) variants were $36.8 \mu \mathrm{M}$ and $30.3 \mu \mathrm{M}$, respectively. The amount of eYFP-WRN variants in all HEK293 transfected cells was similar based on Western blot analyses (Figure 4B). The difference between the hydroquinone's $\mathrm{IC}_{50}$ for the eYFP-WRN(F-R) and eYFP-WRN(L-C) variants was still $\sim 22 \%$ with the PARP1 inhibitor (Figure 4C).

We hypothesized that the overexpression of the eYFP-WRN(L-C) variant, which exhibits a lowest exonuclease activity than the eYFP-WRN(F-R) variant, may also result in the accumulation of unrepaired DNA damage intermediates in cells. To address this issue, we took advantage of the fact that eYFP-WRN expressing cells can be detected by fluorescence under an appropriate fluorescence microscope. More importantly, cells transfected with different eYFP-WRN variants can also be fixed for immunofluoresence analyses with an antibody against phosphorylated $\gamma-\mathrm{H} 2 \mathrm{AX}$. The number of $\gamma-\mathrm{H} 2 \mathrm{AX}$ foci provides an estimate of DNA damage in eYFP-WRN fluorescing cells. To avoid the expression of the endogenous WRN protein in HEK293 that could impinge on the interpretation of the results, we transfected WS fibroblasts (AG11395B) with the two different eYFPWRN variants. We first determined by FACS analysis that the average transfection efficiency for WS fibroblasts was $\sim 20 \%$ for all our constructs. The intensity of eYFPWRN(L-C) and eYFP-WRN(F-R) fluorescence per WS fibroblast was also measured. As indicated in Figure $5 \mathrm{~A}$, the mean fluorescence per cell was not significantly different between eYFP-WRN(L-C) and eYFP-WRN(F-R) transfected WS fibroblasts. Figure $5 \mathrm{~B}$ shows that the number of $\gamma-\mathrm{H} 2 \mathrm{AX}$ foci per cell was significantly less in eYFP-WRN(F-R) expressing fibroblasts than in both eYFP and eYFP-WRN(L-C) expressing fibroblasts. The number of nuclear $\gamma-\mathrm{H} 2 \mathrm{AX}$ foci significantly increased upon hydroquinone treatment (unpaired student $t$-test $P$ $<0.01$ for each transfected construct). However, eYFPWRN(F-R) expressing cells showed a greater protection as the median number of nuclear $\gamma-\mathrm{H} 2 \mathrm{AX}$ foci was significantly less than both eYFP and eYFP-WRN(L-C) expressing cells (Figure 5C). These results indicated that the eYFP-WRN(F-R) variant protected WS fibroblasts more efficiently than the eYFP-WRN(L-C) variant against hydroquinone-induced DNA damage.

Even though the transfection efficiency in WS fibroblasts was much lower than in HEK293, we determined the impact of hydroquinone on cell survival in WS fibroblasts transfected with the eYFP-WRN(L-C) and eYFP-WRN(F-R) variants. Transfected fibroblasts were treated with different concentrations of hydroquinone overnight and cell survival was estimated by a MTT assay. As indicated by the survival curves in Figure 6A, there was a tendency for the eYFP-WRN(L-C) transfected fibroblasts to be more sensitive than the eYFP-WRN(F-R) transfected fibroblasts. The protein transfection levels of eYFP-WRN variants were similar from one transfection experiment to another (Figure 6B and $6 \mathrm{C}$ ). The $\mathrm{IC}_{50}$ for the eYFP-WRN(F-R) and eYFP-WRN(L-C) variants were $75.5 \mu \mathrm{M}$ and $67.7 \mu \mathrm{M}$, respectively ( $12 \%$ difference). Interestingly, there was a significant difference $(P<0.01)$ in cell survival between the eYFP-WRN(F-R) and eYFPWRN(L-C) variants with the highest concentrations of
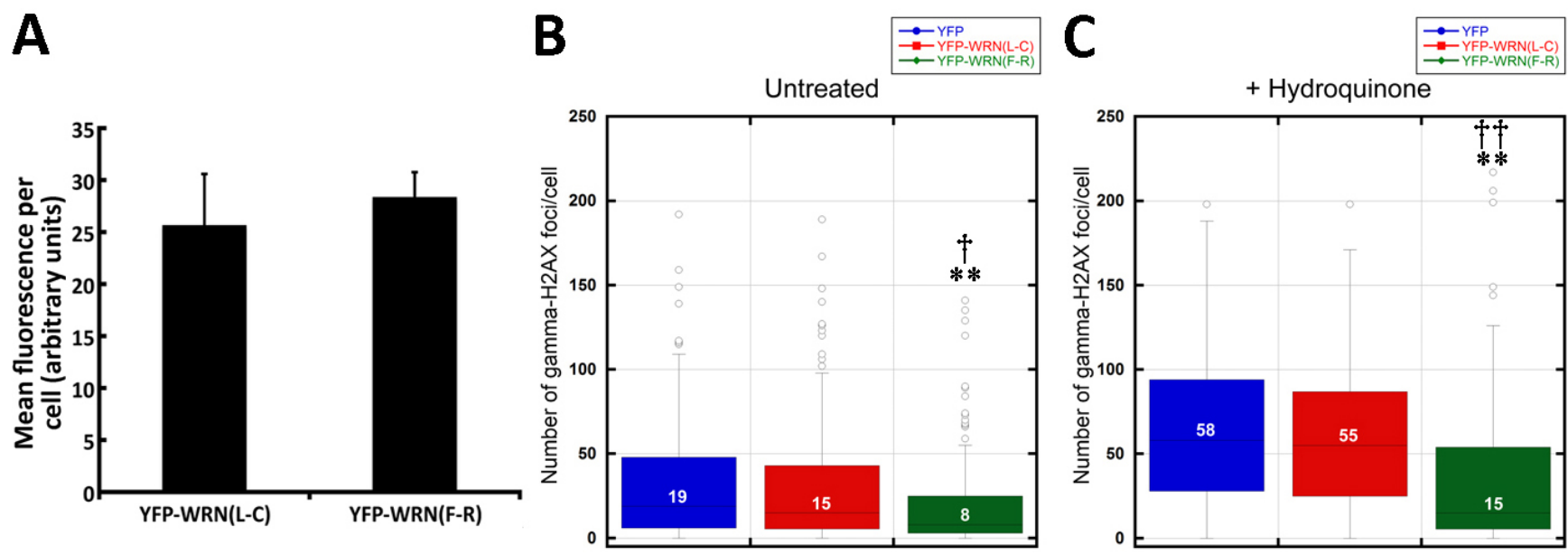

Figure 5: Box plots depicting the distribution of nuclear $\gamma$-H2AX foci in WS fibroblasts (AG11395B) expressing eYFPWRN variants. A. Histogram representing the mean fluorescence intensity per tranfected WS fibroblast for each eYFP-WRN variant. FACS analyses were performed on triplicate transfections. B. WS fibroblasts were transfected with the indicated eYFP-WRN variants. Following overnight transfection, cells were fixed and processed for immunofluorescence analysis with an antibody against phosphorylated $\gamma$-H2AX. Tukey post ANOVA test $P$-values are shown $(* * P<0.01$ compared to eYFP transfected cells and $\dagger P<0.05$ compared to eYFPWRN(L-C) transfected cells). C. Transfected WS fibroblasts were treated with $50 \mu \mathrm{M}$ hydoquinone for four hours and then processed for immunofluorescence analysis with an antibody against phosphorylated $\gamma$-H2AX. Tukey post ANOVA test $P$-values are shown (** $P<0.01$ compared to eYFP transfected cells and $\uparrow \dagger P<0.01$ compared to eYFP-WRN(L-C) transfected cells). The median number of $\gamma$-H2AX foci/ cell is indicated in each box. All experiments were repeated three times. 
hydroquinone treatments (Figure 6D). WS fibroblasts transfected with the eYFP-WRN(L-C) variant were more sensitive to 100 and $200 \mu \mathrm{M}$ of hydroquinone than WS fibroblasts transfected with the eYFP-WRN(F-R) variant.

\section{DISCUSSION}

Previous studies on purified WRN protein have indicated no significant difference with regards to exonuclease and DNA helicase activities when different polymorphic variants of the WRN protein were compared [34]. The two most common polymorphisms (most common in the general population) that were analyzed are single nucleotide polymorphisms (SNPs) affecting C-terminal amino acids 1074 (Leu to Phe) and 1367 (Cys to Arg) of the $W R N$ coding sequence. Although purified WRN variants did not show enzymatic differences, we asked whether such variants interact with their cellular partners with the same affinity. By combining large-scale LC-MS/MS identification of affinity-purified eYFPWRN-associated proteins and bioinformatics-based classification, this study represents the first large-scale proteomic identification of proteins binding onto different polymorphic variants of WRN and provides insights into the pathways that could be modulated by different coding SNPs in the WRN gene. We found that the WRN(L-C) polymorphism causes a significant drop in binding affinity to major DNA damage response factors such as DNA-PKc, KU70, KU86 and PARP1 when expressed in both HEK293 cells and WRN-deficient human fibroblasts derived from a WS subject.

Recently, it has been shown that WRN and KU80 interact directly together through a tandem of C-terminal KU-binding motifs (KBMs) [39]. The deletion of WRN C-terminal KBMs (located at residues 1399-1414 and 1415-1432) reduces the co-precipitation of KU80 by $>95 \%$. This result underscores the importance of WRN C-terminal region for its association with $\mathrm{KU}$ proteins. Therefore, it is possible that WRN C-terminal polymorphisms could modify WRN affinity to KU proteins, which would explain the dramatic loss of KUs that we observed in eYFP-WRN(L-C) affinitypurification extracts. Several studies have indicated that the KU proteins increase the exonuclease activity of purified WRN protein $[12,13,40]$. DNA-PKc, in return, is known to phosphorylate the WRN protein [41] and to inhibit its exonuclease activity depending on the DNA substrates used in the enzymatic assays [42, 43]. However, the literature contains contradictory reports regarding whether the presence of DNA-PKc and KU proteins inhibit the exonuclease activity of the WRN protein [44] or release the inhibitory effect of DNA-PKc on WRN protein [42], especially in the context of PARP1 activation [45]. Using patient-derived WS fibroblasts, we found that the high affinity of the $\mathrm{WRN}(\mathrm{F}-\mathrm{R})$ variant to DNA-PKc/KU complex correlates with high catalytic activity toward a forked DNA structure in contrast to the WRN(L-C) polymorphism. Because of the complex protein composition of the immunoprecipitates that were used in our enzymatic assays, it is impossible at this point to demonstrate unequivocally that interaction with the DNA-PKc/KU/PARP1 complex is actually up regulating WRN activities onto DNA and rule out the contribution of other nuclear proteins listed in the supplementary Table $\mathrm{S} 1$. This might be a challenging task since the dynamic function interplay of many DNA damage response factors is modified in the presence of poly(ADP-ribose), including WRN itself [46].

It has been hypothesized that subjects in the population who bear different coding SNPs in the WRN gene will behave differently in the presence of cytotoxic chemicals pollutants. For example, haplotypic analyses on different WRN coding SNPs indicated that Chinese workers exposed to benzene were more at risk of developing hematotoxicity depending on their polymorphic amino acids at both positions 1074 and 1367 [31, 32]. Indeed, it has been reported that WRN plays an important role in the protection of cells against the toxicity of benzene metabolites [47-49]. Thus, the difference between the polymorphic WRN variants in the population is likely due to how each variant interacts with their nuclear partners in cells and how efficient the different enzymatic activities of the WRN containing complexes are performing in cells. This is consistent with our observation that cells expressing the WRN(L-C) polymorphism are more sensitive to the benzene derived metabolite hydroquinone than WRN(F-R) variant in both HEK293 and WS cell lines. This also correlates with studies reporting that benzene-exposed workers with a WRN(L-C) haplotype are up to $20 \%$ more sensitive to benzene-hematotoxicity than workers with other WRN haplotypes [31].

Benzene metabolites, like reactive hydroquinones, are capable of binding to and damaging macromolecules including DNA, glutathione, tubulin, histones, topoisomerase II and other DNA-related proteins. Moreover, benzene metabolites may give rise to reactive oxygen species [36, 37] in addition to double-strand breaks [50]. We thus tested the impact of the radiomimetic drug neocarzinostatin and hydrogen peroxide on HEK293 cells transfected with the eYFP-WRN variants that coimmunoprecipitated the highest and the lowest amount of DNA-PKc, KU86, KU70, and PARP1. Importantly, the addition of the drug hydroquinone did not change the amount of DNA-PKc, KU86, KU70, and PARP1 co-immunoprecipitated with these variants even though the eYFP-WRN(L-C) variant was more sensitive to the drug than the eYFP-WRN(F-R) variant. The WRN variant containing a phenylalanine at position 1074 and an arginine at position 1367 co-immunoprecipitated more DNA-PKc, KU86, KU70, PARP1 in the presence or absence of hydroquinone than the WRN variant containing 

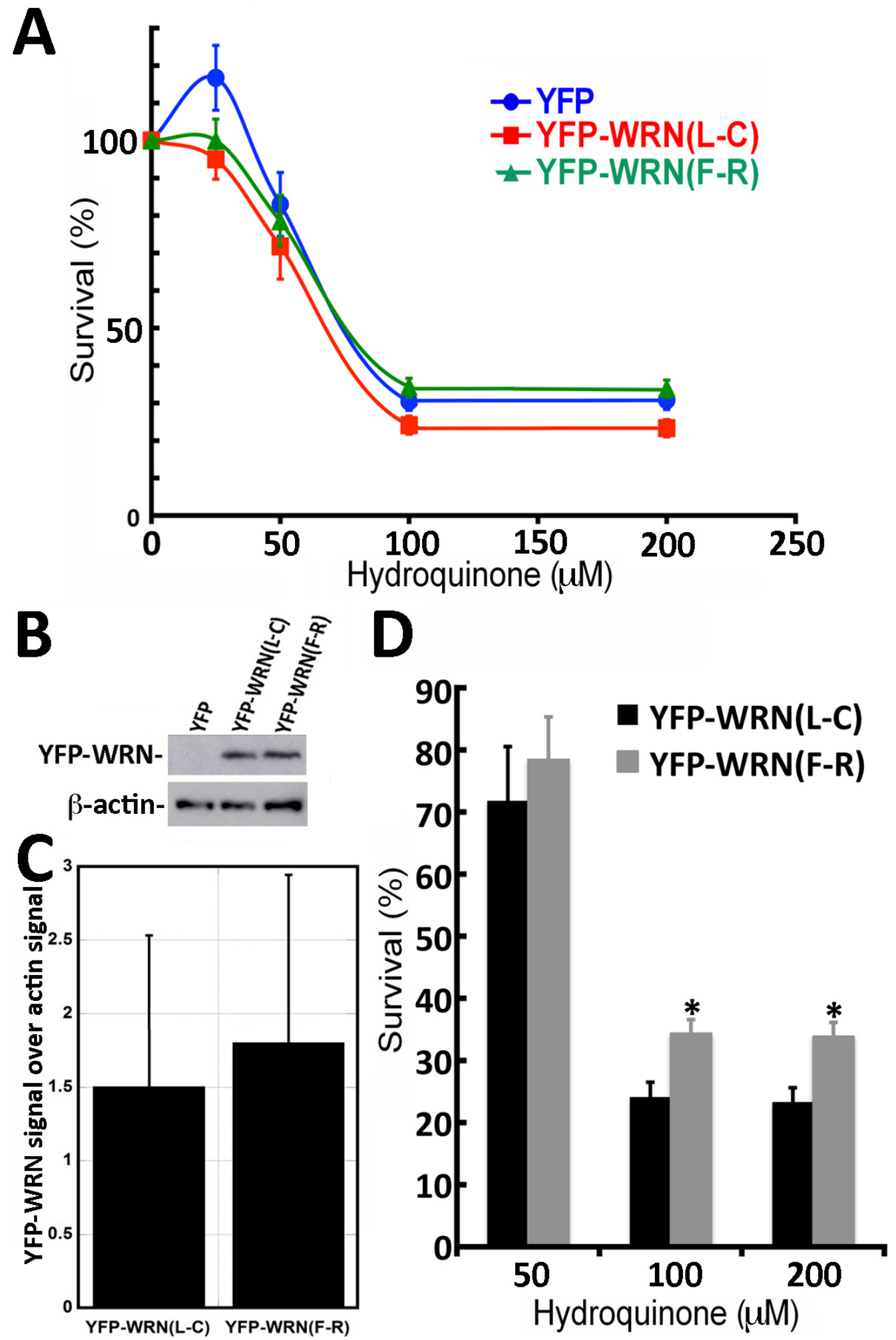

Figure 6: Dose-response curves of WS fibroblasts (AG11395B) expressing eYFP-WRN(L-C) and eYFP-WRN(F-R) variants exposed to hydroquinone as determined by the MTT assay. A. Graph showing the hydroquinone sensitivity of WS fibroblasts expressing the eYFP-WRN variants as determined by MTT assay. Experiments were repeated 12 times. Bars represent SEM. B. Representative Western blot showing the expression of the eYFP-WRN variants in transfected WS fibroblasts. $\beta$-actin was used as a loading control. C. Histogram presenting the ratio of eYFP-WRN signal over $\beta$-actin signal from nine Western blots. Bars represent SE. D. Histogram representing the \% survival of eYFP-WRN(L-C) and eYFP-WRN(F-R) transfected WS fibroblasts exposed to the indicated concentration of hydroquinone for 24 hours. Bars represent SEM for 12 transfections. (*Unpaired student $t$-test $P$-value $<0.01$ compared to the eYFP-WRN(L-C) variant). 
leucine at position 1074 and a cysteine at position 1367. These results indicate that WRN/DNA-PKc, WRN/ KU or WRN/PARP1complexes pre-exist in untreated HEK293 cells. The amount of these cellular complexes is determined by the coding SNPs in cells. The survival tests with the radiomimetic drug neocarzinostatin and hydrogen peroxide indicated that eYFP-WRN(L-C) transfected HEK293 cells were more sensitive to hydrogen peroxide (i.e. oxidized DNA damage) than the eYFP-WRN(F-R) variant but no difference in cell survival between these variants were observed with neocarzinostatin (i.e. doublestrand breaks). Importantly, deficient repair of oxidative DNA damage is commonly associated with premature aging and age-related diseases [51].

Unrepaired hydroquinone-induced DNA lesions lead to DNA breaks that can be monitored by the presence of phosphorylated $\gamma-\mathrm{H} 2 \mathrm{AX}$ nuclear foci. Interestingly, eYFP-WRN(F-R) expressing WS fibroblasts exhibited significantly less $\gamma$-H2AX nuclear foci (i.e. doublestrand breaks) than WS fibroblasts expressing the eYFPWRN(L-C) variant. Since the eYFP-WRN(F-R) variant co-immunoprecipitated more DNA repair protein partners and exhibited higher nuclease activities than the eYFPWRN(L-C) variant in WS fibroblasts, this suggests a better regulation and repair of DNA damage by eYFP-WRN(F$\mathrm{R})$-containing protein complex in cells.

In summary, our results indicate that different polymorphisms in the WRN protein will impact hydroquinone genotoxicity through the modulation of DNA damage response-associated protein complex stoichiometry. Such results may imply that a WRN variant with a lower affinity for positive regulators during oxidative stress will have more deleterious effects on overall cell survival because of alterations in the fine-tuning of its enzymatic activity under DNA repair conditions. The higher number of $\gamma-\mathrm{H} 2 \mathrm{AX}$ nuclear foci in WS cells expressing the eYFP-WRN(L-C) variant compared to the eYFP-WRN(F-R) variant is consistent with such findings. Finally, our results underscore the importance of functional haplotype-based analyses to appreciate the contribution of a group of proteins engaged together to produce particular phenotypic outcomes.

\section{MATERIALS AND METHODS}

\section{Cell line and expression vectors}

Human 293 embryonic kidney cells (HEK293; ATCC cat\# CRL-1573) and the WS fibroblasts AG11395B (from the Coriell cell repositories) were maintained in Dulbecco's Modified Eagle Medium (DMEM) supplemented with $10 \%$ fetal bovine serum, penicillin $(250 \mathrm{IU} / \mathrm{mL})$, and streptomycin $(250 \mu \mathrm{L} / \mathrm{mL})$ at $37^{\circ} \mathrm{C}$ in atmosphere of $5 \% \mathrm{CO}_{2}$. The eYFP control vector was purchased from Clontech (Mountain View, CA). The eYFP-WRN construct is described elsewhere [52]. The GenBank Accession code for the wild type cDNA sequence used in this study is NM_000553.4. The Leu and Cys at positions 1074 and 1367 of the WRN protein were respectively changed for Phe and Arg with the QuickChange site-directed mutagenesis kit from Stratagene (La Jolla, CA) to generate the different YFPWRN polymorphic variants. These changes correspond to the single nucleotide polymorphisms rs 1346044: $\mathrm{T}>\mathrm{C}$ and rs 1801195:G $>$ T in the human $W R N$ gene, respectively.

\section{eYFP-WRN Immunoprecipitation}

HEK293 cells were seeded onto nine $150 \mathrm{~mm}$ cell-culture dishes and grown up to $80-90 \%$ confluency. Transfections were performed with the Effectene transfection reagent from Qiagen, Inc. (Mississauga, ON). The transfection efficiency in HEK293 cells was $>80 \%$. All further steps were performed $24 \mathrm{~h}$ after the transfections on ice or at $4{ }^{\circ} \mathrm{C}$. Two PBS washes were carried out prior to the extraction (cell scraping) with 2 $\mathrm{mL} /$ plates of lysis buffer [40 mM HEPES $\mathrm{pH} 7.5,120 \mathrm{mM}$ $\mathrm{NaCl}, 0.3 \%$ CHAPS, $1 \mathrm{mM}$ EDTA, Complete protease inhibitor cocktail (Roche Applied Science, Indianapolis, IN)]. Benzonase $(25 \mathrm{U} / \mathrm{mL})$ and RNase A $(100 \mu \mathrm{g} / \mathrm{mL})$ (EMD, Gibbstown, NJ) were also added in the buffer. Cells were kept on ice for 15 min and gently lysed for another $15 \mathrm{~min}$ on a rotating device. Cell extracts were centrifuged for $5 \mathrm{~min}$ at $3400 \mathrm{rpm}$ to remove cellular debris. Immunoprecipitation experiments were performed using Dynabeads magnetic beads covalently coupled with Protein G (Invitrogen, Burlington, ON). The Dynabeads were washed once with $1 \mathrm{~mL}$ of $0.1 \mathrm{M}$ sodium acetate buffer, $\mathrm{pH}$ 5.0, coated with 10-15 $\mu \mathrm{g}$ of mouse monoclonal anti-GFP antibody, which also recognizes eYFP protein (Roche Applied Science, Indianapolis, IN). The antibodycoupled Dynabeads were incubated for $1 \mathrm{~h}$ at room temperature with $1 \mathrm{~mL}$ of PBS containing $1 \%(\mathrm{w} / \mathrm{v})$ BSA (Sigma-Aldrich, Oakville, ON) to block nonspecific antibody binding sites. The beads were finally washed three times with $2 \mathrm{~mL}$ of lysis buffer and added to the protein extract for $4 \mathrm{~h}$ incubation with gentle agitation in a cold room. (Protein extracts had been pre-cleared with empty Dynabeads for $45 \mathrm{~min}$ in a cold room before adding the anti-GFP coupled beads.) Samples were then washed three times with $2 \mathrm{vol}$ of lysis buffer for $5 \mathrm{~min}$. Protein complexes were eluted using $150 \mu \mathrm{L}$ of $2 \mathrm{X}$ Laemmli sample buffer containing 5\% $\beta$-mercaptoethanol and boiled for $5 \mathrm{~min}$ in a water bath. Proteins were resolved using 4-12\% Criterion XT Bis-Tris gradient gel (Bio-Rad, Mississauga, Canada) and stained with Sypro Ruby (BioRad, Mississauga, ON) according to the manufacturer's instructions. Images were acquired using the Geliance CCD-based imaging system (Perkin- Elmer, Shelton, CT). 


\section{LC-MS/MS analysis}

SDS-PAGE protein lanes corresponding to antieYFP immunoprecipitated extracts were cut into 33 gel slices per lane using a disposable lane picker (The Gel Company, San Francisco, CA). Gel slices were deposited into 96-well plates. In-gel protein digest was performed on a MassPrep liquid handling station (Waters, Mississauga, Canada) according to the manufacturer's specifications and using sequencing-grade modified trypsin (Promega, Madison, WI). Peptide extracts were dried out using a SpeedVac. Peptide extracts were separated by online reversed-phase (RP) nanoscale capillary LC (nanoLC) and analyzed by electrospray MS (ES MS/MS). The experiments were performed on a Thermo Surveyor MS pump connected to a LTQ linear ion trap mass spectrometer (Thermo Electron, San Jose, CA) equipped with a nanoelectrospray ion source (Thermo Electron, San Jose, CA). Peptide separation took place within a PicoFrit column BioBasic C18, $10 \mathrm{~cm}$ x $0.075 \mathrm{~mm}$ internal diameter (New Objective, Woburn, MA) with a linear gradient from $2 \%$ to $50 \%$ solvent B (acetonitrile, $0.1 \%$ formic acid) in $30 \mathrm{~min}$, at $200 \mathrm{~nL} / \mathrm{min}$. Mass spectra were acquired using data-dependent acquisition mode (Xcalibure software, version 2.0). Each full-scan mass spectrum $(400-2000 \mathrm{~m} / \mathrm{z})$ was followed by collisioninduced dissociation of the seven most intense ions. The dynamic exclusion function was enabled (30 s exclusion), and the relative collisional fragmentation energy was set to $35 \%$.

\section{Interpretation of tandem MS spectra}

Tandem mass spectra were extracted by Mascot Deamon with Extract_MSN.exe. Charge state deconvolution and deisotoping were not performed. All MS/MS samples were analyzed using Mascot (Matrix Science, London, UK; version 2.4.1) and X! Tandem (The GPM, thegpm.org; version CYCLONE (2010.12.01.1)). Mascot was set up to search the Homo sapiens protein database (69137 entries) assuming the digestion enzyme trypsin. X! Tandem was set up to search a subset of database also assuming trypsin. Mascot and X! Tandem were searched with a fragment ion mass tolerance of 0.50 $\mathrm{Da}$ and a parent ion tolerance of 2.0 Da. Iodoacetamide derivative of cysteine was specified in Mascot and X! Tandem as a fixed modification. Oxidation of methionine was specified in Mascot as a variable modification. Pyroglu from $\mathrm{E}$ of the $\mathrm{n}$-terminus, s-carbamoylmethylcysteine cyclization ( $\mathrm{N}$-terminus) of the $\mathrm{n}$-terminus and oxidation of methionine were specified in $\mathrm{X}$ ! Tandem as variable modifications.

\section{Criteria for protein identification}

Scaffold (version 4.2.0; Proteome Software, Inc., Portland, OR) was used to validate MS/MS-based peptide and protein identifications. Peptide identifications were accepted if they could be established at $>95.0 \%$ probability as specified by the Peptide Prophet algorithm [53]. Protein identifications were accepted if they could be established at $>95.0 \%$ probability and contained at least two identified peptides. Protein probabilities were assigned by the Protein Prophet algorithm [54]. Proteins that contained similar peptides and could not be differentiated based on MS/MS analysis alone were grouped to satisfy the principles of parsimony. For this study, a protein interacting with one of the WRN variants was considered positive if at least two MS/MS spectra could be assigned to a corresponding peptide. Proteins identified in a control HEK293 immunoprecipitation extract (expressing eYFP alone) were considered artifacts and removed from the final list of potential eYFP-WRN interacting proteins.

\section{Immunoblotting}

The immunoprecipitated proteins were eluted from the DynaBeads, separated on SDS-PAGE, and then transferred onto $0.2 \mu \mathrm{m}$ nitrocellulose membrane (BioRad). After incubating $1 \mathrm{~h}$ with blocking solution (PBS-T containing 5\% nonfat milk), the membrane was probed overnight at $4{ }^{\circ} \mathrm{C}$ with either rabbit polyclonal antibodies against KU70, KU86, PARP1 (Santa Cruz Biotechnology, SantaCruz, CA), or a mouse monoclonal antibody against DNA-PKc (Oncogene Research Products, Cambridge, MA). The antibody against GFP (or eYFP) was purchased from BD Biosciences (Palo Alto, CA). After washing with PBS-T, species-specific horseradish peroxidaseconjugated secondary antibody was added for $2 \mathrm{~h}$ at room temperature. Signals were generated with Western Lightning Chemiluminescence reagent plus kit (GE Healthcare Limited, Piscataway, NJ).

\section{Exonuclease and helicase activities of immunoprecipitated eYFP-WRN}

One $100 \mathrm{~mm}$ Petri dish of WS fibroblasts AG11395B $\left(1.8 \times 10^{8}\right.$ cells) was transfected with $6 \mu \mathrm{g}$ of the eYFP or the eYFP-WRN plasmids with the TurboFectin 8.0 transfection reagent from Origene (Rockville, MD). The next day, eYFP and eYFP-WRN transfected cells were lysed in $1 \mathrm{~mL}$ of a stringent buffer $[50 \mathrm{mM}$ Tris- $\mathrm{HCl} \mathrm{pH}$ 8.0, $150 \mathrm{mM} \mathrm{NaCl}, 1.0 \%$ NP-40, 0.1\% SDS, 0.5\% Sodium deoxycholate, Complete protease inhibitor cocktail (Roche Applied Science, Indianapolis, IN)]. No benzonase and RNAse A was added in the lysis buffer. eYFP and eYFPWRN were immunoprecipitated with $2 \mu \mathrm{g}$ of an antibody 
against YFP and magnetic beads as described above. Immunoprecipitation was carried out for $2 \mathrm{~h}$ in a cold room. Beads containing the immune complexes were washed once with $1 \mathrm{~mL}$ of a buffer containing $20 \mathrm{mM}$ Tris- $\mathrm{HCl} \mathrm{pH}$ 8.0, $0.5 \mathrm{M} \mathrm{NaCl}, 1 \mathrm{mM}$ EDTA, $0.5 \mathrm{mM}$ DTT, 0,5\% NP-40, 25\% Glycerol, 0.2 mM PMSF. Beads were then washed twice with $2 \mathrm{~mL}$ of a buffer containing $20 \mathrm{mM}$ Tris- $\mathrm{HCl} \mathrm{pH} 8.0,150 \mathrm{mM} \mathrm{NaCl}, 25 \%$ Glycerol, $0.5 \%$ NP-40, 0.05\% Sodium deoxycholate, $0.005 \%$ SDS. Finally, beads were resuspended in $15 \mu \mathrm{L}$ of buffer $(25$ $\mathrm{mM}$ Tris- $\mathrm{HCl} \mathrm{pH}$ 8.0, $0.5 \mathrm{mM}$ EDTA, $1 \mathrm{mM}$ DTT, 0.05\% NP-40, 25\% glycerol). Resuspended beads containing the immune complexes $(\sim 0.1 \mu \mathrm{g} / \mu \mathrm{L}$ of antibody) were diluted as indicated in the figures in assay reaction buffer $(40 \mathrm{mM}$ Tris- $\mathrm{HCl} \mathrm{pH} 7.4,4 \mathrm{mM} \mathrm{MgCl}, 0.1 \mathrm{mg} / \mathrm{mL}$ BSA, $5 \mathrm{mM}$ DTT, and $100 \mathrm{nM}$ of splayed arms labeled on one DNA strand) [35]. The reaction was incubated for $20 \mathrm{~min}$ at $37^{\circ} \mathrm{C}$, and stopped with one-fifth volume of Stop buffer (40\% glycerol, 50 mM EDTA, 2\% SDS, 3\% xylene cyanol and $3 \%$ bromophenol blue). Reaction samples were loaded on a $6 \%$ PAGE/TBE $1 \mathrm{X}$ for autoradiography. The intensity of the bands representing the digested and undigested DNA structures on the autoradiogram was measured with Adobe Photoshop version 9.0.2.

\section{Drug treatments and sulforhodamine B colorimetric assay for HEK293 cells}

HEK293 cells were transfected with the indicated constructs and allowed to grow for 24 hours. The next day, 10,000 cells were seeded per well on a 96 -well plate and incubated at $37^{\circ} \mathrm{C}$ for 24 hours. Different concentrations of either the radiomimetic drug neocarzinostatin, the benzene metabolite hydroquinone, or hydrogen peroxide (SigmaAldrich, Oakville, ON) were added to the cells in triplicate and cells were then allowed to grow for an additional 18 hours. When indicated, transfected cells were treated for one hour with $1 \mu \mathrm{M}$ of the PARP1 inhibitor BMN-673 (also known as talazoparib (Biomarin Pharmaceuticals), Selleckchem, Houston, TX) prior to the addition of different concentrations of hydroquinone. Cells were fixed with tricholoroacetic acid (10\% w/v) and stained $30 \mathrm{~min}$ with sulforhodamine B as described [55]. The percentage of cell survival was calculated relative to untreated cells. The survival curves were plotted with GraphPad Prism 6.7 software via nonlinear regression. The Hill equation was used to estimate $\mathrm{IC}_{50}$ values, which are defined as the drug concentrations required to kill $50 \%$ of the cells.

\section{Immunofluorescence assays}

WS fibroblasts (AG11395B) were transfected with $400 \mathrm{ng}$ of eYFP, eYFP-WRN(L-C), or eYFP-WRN(F-R) constructs with Lipofectamine 2000 (Thermo Fisher Scientific Inc., Waltham, MA). The range of expression of the eYFP-WRN constructs in each transfected cell was evaluated by FACS analysis at the flow cytometry laboratory of the Centre de Recherche du CHU de Québec, (Québec City, Canada). For drug treatments, one day after the transfection, transfected cells were treated with $50 \mu \mathrm{M}$ of hydroquinone for four hours. Cells were then washed twice in PBS, fixed with $2 \%$ paraformaldehyde in PBS for $10 \mathrm{~min}$, washed with TBS and fixed with cold methanol $\left(-20^{\circ} \mathrm{C}\right)$ for $5 \mathrm{~min}$. Next, cells were washed once in TBS, permeabilized $5 \mathrm{~min}$ with PBS (0.2\% Triton X-100) and washed three times 5 min with TBS. Then, cells were quenched with $0.1 \%$ sodium borohydride $5 \mathrm{~min}$, washed once with TBS and blocked in PBS (10\% goat serum and 1\% BSA) one hour. Cells were then incubated one hour with an anti phosphohistone $\gamma-\mathrm{H} 2 \mathrm{AX}$ ((Ser139) from EMD Millipore Corp., Billerica, MA, USA) diluted in $1 \%$ BSA/TBS. Cells were washed three times $5 \mathrm{~min}$ with TBS and incubated one hour with the appropriate secondary antibody $(1 \%$ BSA/TBS) conjugated to a fluorophore (Alexa Fluor 568 (red) from Life Technologies). Cells were washed three times 10 min with TBS and coverslips were mounted onto slides with PBS-glycerol (90\%) containing 1mg/ml paraphenylenediamine and $0.2 \mathrm{mg} / \mathrm{ml}$ of 4,6-diamidino-2phenylindole (DAPI). For $\gamma$-H2AX scoring, images were obtained using a Leica CTR 6000 microscope. Number of foci per cell was automatically counted following background subtraction and deconvolution using Volocity software v 5.5 (Perkin-Elmer Improvision). Foci were scored according to intensity within a $\leq 0.7 \mu \mathrm{M}$ radius. Approximately, 50 to 60 fluorescent cells/replicates were examined for each construct by two different persons. Transfection experiments were performed in triplicates and repeated thrice. Results are presented as box plots. One-way ANOVA followed by Tukey's HSD (honest significant difference) Test for post-ANOVA pair-wise comparisons were performed to determine significant differences with values of $P<0.05$.

\section{Hydroquinone treatments and MTT assay for WS fibroblasts (AG11395B)}

The reduction of tetrazolium salts is a reliable way to examine cell proliferation. The yellow tetrazolium MTT (3-(4, 5-dimethylthiazolyl-2)-2, 5-diphenyltetrazolium bromide) is reduced by metabolically active cells, in part by the action of dehydrogenase enzymes, to generate reducing equivalents such as NADH and NADPH. The resulting intracellular purple formazan can be solubilized and quantified by spectrophotometric means. Briefly, WS fibroblasts were transfected with the indicated constructs using the TurboFectin reagents (Origene) and allowed to grow for 24 hours. The next day, 4,000 cells were seeded per well on a 96 -well plate and incubated at $37^{\circ} \mathrm{C}$ for six hours. Different concentrations of the benzene metabolite 
hydroquinone (Sigma-Aldrich, Oakville, ON) were then added to the cells in triplicate. Transfected cells were allowed to grow for an additional 24 hours. The next day, wells were rinsed with PBS and $200 \mu \mathrm{L}$ of MTT reagent $(0.25 \mu \mathrm{g} / \mu \mathrm{L}$ in fresh medium) was added to each well and plates were incubated at $37^{\circ} \mathrm{C}$ for four hours. The medium was removed and $150 \mu \mathrm{L}$ of DMSO was added for spectrophotometric measurements. Absorbance was read at $540 \mathrm{~nm}$ and $670 \mathrm{~nm}$.

\section{ACKNOWLEDGMENTS}

We thank Mrs. A. Rodrigue and S. Proulx from the Centre de Recherche sur le Cancer de l'Université Laval, QC, Canada for technical assistance. The Proteomics Platform of the Québec Genomics Center provided mass spectrometry analysis. G.G.P. holds a Tier 1 Canada chair in proteomics and J.Y.M. is a FRQS Chercheur National Investigator.

\section{CONFLICTS OF INTEREST}

None to declare.

\section{FUNDING}

This work was supported by grants from the Canadian Institutes of Health Research (CIHR) to J.Y.M. (grant number FRN-111063) and M.L. (grant number MOP-67153).

\section{REFERENCES}

1. Epstein CJ, Martin GM, Schultz AL, Motulsky AG. Werner's syndrome a review of its symptomatology, natural history, pathologic features, genetics and relationship to the natural aging process. Medicine (Baltimore). 1966; 45: 177221.

2. Salk D. Werner's syndrome: a review of recent research with an analysis of connective tissue metabolism, growth control of cultured cells, and chromosomal aberrations. Hum Genet. 1982; 62: 1-5.

3. Ozgenc A, Loeb LA. Current advances in unraveling the function of the Werner syndrome protein. Mutat Res. 2005; 577: 237-51.

4. Yu CE, Oshima J, Fu YH, Wijsman EM, Hisama F, Alisch R, Matthews S, Nakura J, Miki T, Ouais S, Martin GM, Mulligan J, Schellenberg GD. Positional cloning of the Werner's syndrome gene. Science. 1996; 272: 258-62.

5. Schonberg S, Niermeijer MF, Bootsma D, Henderson E, German J. Werner's syndrome: proliferation in vitro of clones of cells bearing chromosome translocations. Am J Hum Genet. 1984; 36: 387-97.

6. Scappaticci S, Forabosco A, Borroni G, Orecchia G, Fraccaro M. Clonal structural chromosomal rearrangements in lymphocytes of four patients with Werner's syndrome. Ann Genet. 1990; 33: 5-8.

7. Lebel M. Werner syndrome: genetic and molecular basis of a premature aging disorder. Cell Mol Life Sci. 2001; 58: 857-67.

8. Constantinou A, Tarsounas M, Karow JK, Brosh RM, Bohr VA, Hickson ID, West SC. Werner's syndrome protein (WRN) migrates Holliday junctions and co-localizes with RPA upon replication arrest. EMBO Rep. 2000; 1: 80-4.

9. Prince PR, Emond MJ, Monnat RJ, Jr. Loss of Werner syndrome protein function promotes aberrant mitotic recombination. Genes Dev. 2001; 15: 933-8.

10. Saintigny Y, Makienko K, Swanson C, Emond MJ, Monnat RJ, Jr. Homologous recombination resolution defect in werner syndrome. Mol Cell Biol. 2002; 22: 6971-8.

11. Orren DK, Brosh RM, Jr., Nehlin JO, Machwe A, Gray MD, Bohr VA. Enzymatic and DNA binding properties of purified WRN protein: high affinity binding to singlestranded DNA but not to DNA damage induced by 4NQO. Nucleic Acids Res. 1999; 27: 3557-66.

12. Cooper MP, Machwe A, Orren DK, Brosh RM, Ramsden $\mathrm{D}$, Bohr VA. Ku complex interacts with and stimulates the Werner protein. Genes Dev. 2000; 14: 907-12.

13. Li B, Comai L. Functional interaction between $\mathrm{Ku}$ and the werner syndrome protein in DNA end processing. J Biol Chem. 2000; 275: 28349-52.

14. Popp O, Veith S, Fahrer J, Bohr VA, Burkle A, Mangerich A. Site-specific noncovalent interaction of the biopolymer poly(ADP-ribose) with the Werner syndrome protein regulates protein functions. ACS Chem Biol. 2013; 8: 17988.

15. Veith S, Mangerich A. RecQ helicases and PARP1 team up in maintaining genome integrity. Ageing Res Rev. 2015; 23: 12-28.

16. von Kobbe C, Harrigan JA, May A, Opresko PL, Dawut L, Cheng WH, Bohr VA. Central role for the Werner syndrome protein/poly(ADP-ribose) polymerase 1 complex in the poly(ADP-ribosyl)ation pathway after DNA damage. Mol Cell Biol. 2003; 23: 8601-13.

17. Lebel M, Lavoie J, Gaudreault I, Bronsard M, Drouin R. Genetic cooperation between the Werner syndrome protein and poly(ADP-ribose) polymerase-1 in preventing chromatid breaks, complex chromosomal rearrangements, and cancer in mice. Am J Pathol. 2003; 162: 1559-69.

18. Lauper JM, Krause A, Vaughan TL, Monnat RJ, Jr. Spectrum and risk of neoplasia in werner syndrome: a systematic review. PLoS One. 2013; 8: e59709.

19. Nakayama R, Sato Y, Masutani M, Ogino H, Nakatani F, Chuman H, Beppu Y, Morioka H, Yabe H, Hirose H, Sugimura H, Sakamoto H, Ohta T, et al. Association of a missense single nucleotide polymorphism, Cys1367Arg of the WRN gene, with the risk of bone and soft tissue sarcomas in Japan. Cancer Sci. 2008; 99: 333-9.

20. Shen M, Zheng T, Lan Q, Zhang Y, Zahm SH, Wang SS, 
Holford TR, Leaderer B, Yeager M, Welch R, Kang D, Boyle P, Zhang B, et al. Polymorphisms in DNA repair genes and risk of non-Hodgkin lymphoma among women in Connecticut. Hum Genet. 2006; 119: 659-68.

21. Shen M, Purdue MP, Kricker A, Lan Q, Grulich AE, Vajdic CM, Turner J, Whitby D, Chanock S, Rothman N, Armstrong BK. Polymorphisms in DNA repair genes and risk of non-Hodgkin's lymphoma in New South Wales, Australia. Haematologica. 2007; 92: 1180-5.

22. Hill DA, Wang SS, Cerhan JR, Davis S, Cozen W, Severson RK, Hartge P, Wacholder S, Yeager M, Chanock SJ, Rothman N. Risk of non-Hodgkin lymphoma (NHL) in relation to germline variation in DNA repair and related genes. Blood. 2006; 108: 3161-7.

23. Vineis $\mathrm{P}$, Manuguerra M, Kavvoura FK, Guarrera S, Allione A, Rosa F, Di Gregorio A, Polidoro S, Saletta F, Ioannidis JP, Matullo G. A field synopsis on low-penetrance variants in DNA repair genes and cancer susceptibility. J Natl Cancer Inst. 2009; 101: 24-36.

24. Khayat AS, Lobo Gatti L, Moura Lima E, de Assumpcao PP, Nascimento Motta FJ, Harada ML, Casartelli C, Marques Payao SL, Cardoso Smith MA, Burbano RR. Polymorphisms of the TP53 codon 72 and WRN codon 1367 in individuals from Northern Brazil with gastric adenocarcinoma. Clin Exp Med. 2005; 5: 161-8.

25. Li T, Suo Q, He D, Du W, Yang M, Fan X, Liu J. Esophageal cancer risk is associated with polymorphisms of DNA repair genes MSH2 and WRN in Chinese population. J Thorac Oncol. 2012; 7: 448-52.

26. Wirtenberger $M$, Frank $B$, Hemminki K, Klaes R, Schmutzler RK, Wappenschmidt B, Meindl A, Kiechle M, Arnold N, Weber BH, Niederacher D, Bartram CR, Burwinkel B. Interaction of Werner and Bloom syndrome genes with p53 in familial breast cancer. Carcinogenesis. 2006; 27: 1655-60.

27. Olson JE, Wang X, Pankratz VS, Fredericksen ZS, Vachon CM, Vierkant RA, Cerhan JR, Couch FJ. Centrosomerelated genes, genetic variation, and risk of breast cancer. Breast Cancer Res Treat. 2011; 125: 221-8.

28. Wang Z, Xu Y, Tang J, Ma H, Qin J, Lu C, Wang X, Hu Z, Wang X, Shen H. A polymorphism in Werner syndrome gene is associated with breast cancer susceptibility in Chinese women. Breast Cancer Res Treat. 2009; 118: 16975.

29. Rudd MF, Webb EL, Matakidou A, Sellick GS, Williams RD, Bridle H, Eisen T, Houlston RS. Variants in the GHIGF axis confer susceptibility to lung cancer. Genome Res. 2006; 16: 693-701.

30. Wang L, Kaku H, Huang P, Xu K, Yang K, Zhang J, Li M, Xie L, Wang X, Sakai A, Watanabe M, Nasu Y, Shimizu K, et al. Single nucleotide polymorphism WRN Leu1074Phe is associated with prostate cancer susceptibility in Chinese subjects. Acta Med Okayama. 2011; 65: 315-23.

31. Shen M, Lan Q, Zhang L, Chanock S, Li G, Vermeulen R,
Rappaport SM, Guo W, Hayes RB, Linet M, Yin S, Yeager $\mathrm{M}$, Welch R, et al. Polymorphisms in genes involved in DNA double-strand break repair pathway and susceptibility to benzene-induced hematotoxicity. Carcinogenesis. 2006; 27: 2083-9.

32. Lan Q, Zhang L, Shen M, Jo WJ, Vermeulen R, Li G, Vulpe C, Lim S, Ren X, Rappaport SM, Berndt SI, Yeager M, Yuenger J, et al. Large-scale evaluation of candidate genes identifies associations between DNA repair and genomic maintenance and development of benzene hematotoxicity. Carcinogenesis. 2009; 30: 50-8.

33. Bohr VA, Metter EJ, Harrigan JA, von Kobbe C, Liu JL, Gray MD, Majumdar A, Wilson DM, 3rd, Seidman MM. Werner syndrome protein 1367 variants and disposition towards coronary artery disease in Caucasian patients. Mech Ageing Dev. 2004; 125: 491-6.

34. Kamath-Loeb AS, Welcsh P, Waite M, Adman ET, Loeb LA. The enzymatic activities of the Werner syndrome protein are disabled by the amino acid polymorphism R834C. J Biol Chem. 2004; 279: 55499-505.

35. Lachapelle S, Gagne JP, Garand C, Desbiens M, Coulombe Y, Bohr VA, Hendzel MJ, Masson JY, Poirier GG, Lebel M. Proteome-wide identification of WRN-interacting proteins in untreated and nuclease-treated samples. J Proteome Res. 2011; 10: 1216-27.

36. Kolachana P, Subrahmanyam VV, Meyer KB, Zhang L, Smith MT. Benzene and its phenolic metabolites produce oxidative DNA damage in HL60 cells in vitro and in the bone marrow in vivo. Cancer Res. 1993; 53: 1023-6.

37. Luo L, Jiang L, Geng C, Cao J, Zhong L. Hydroquinoneinduced genotoxicity and oxidative DNA damage in HepG2 cells. Chem Biol Interact. 2008; 173: 1-8.

38. Shen Y, Rehman FL, Feng Y, Boshuizen J, Bajrami I, Elliott R, Wang B, Lord CJ, Post LE, Ashworth A. BMN 673, a novel and highly potent PARP1/2 inhibitor for the treatment of human cancers with DNA repair deficiency. Clin Cancer Res. 2013; 19: 5003-15.

39. Grundy GJ, Rulten SL, Arribas-Bosacoma R, Davidson K, Kozik Z, Oliver AW, Pearl LH, Caldecott KW. The Kubinding motif is a conserved module for recruitment and stimulation of non-homologous end-joining proteins. Nat Commun. 2016; 7: 11242.

40. Karmakar P, Snowden CM, Ramsden DA, Bohr VA. Ku heterodimer binds to both ends of the Werner protein and functional interaction occurs at the Werner N-terminus. Nucleic Acids Res. 2002; 30: 3583-91.

41. Kusumoto-Matsuo R, Ghosh D, Karmakar P, May A, Ramsden D, Bohr VA. Serines 440 and 467 in the Werner syndrome protein are phosphorylated by DNA-PK and affects its dynamics in response to DNA double strand breaks. Aging (Albany NY). 2014; 6: 70-81. doi: 10.18632/ aging.100629.

42. Yannone SM, Roy S, Chan DW, Murphy MB, Huang S, Campisi J, Chen DJ. Werner syndrome protein is regulated 
and phosphorylated by DNA-dependent protein kinase. J Biol Chem. 2001; 276: 38242-8.

43. Kusumoto-Matsuo R, Opresko PL, Ramsden D, Tahara H, Bohr VA. Cooperation of DNA-PKes and WRN helicase in the maintenance of telomeric D-loops. Aging (Albany NY). 2010; 2: 274-84. doi: 10.18632/aging. 100141.

44. Karmakar P, Piotrowski J, Brosh RM, Jr., Sommers JA, Miller SP, Cheng WH, Snowden CM, Ramsden DA, Bohr VA. Werner protein is a target of DNA-dependent protein kinase in vivo and in vitro, and its catalytic activities are regulated by phosphorylation. J Biol Chem. 2002; 277: 18291-302.

45. Khadka P, Hsu JK, Veith S, Tadokoro T, Shamanna RA, Mangerich A, Croteau DL, Bohr VA. Differential and Concordant Roles for Poly(ADP-Ribose) Polymerase 1 and Poly(ADP-Ribose) in Regulating WRN and RECQL5 Activities. Mol Cell Biol. 2015; 35: 3974-89.

46. Krietsch J, Rouleau M, Pic E, Ethier C, Dawson TM, Dawson VL, Masson JY, Poirier GG, Gagne JP. Reprogramming cellular events by poly(ADP-ribose)binding proteins. Mol Aspects Med. 2013; 34: 1066-87.

47. Garige M, Sharma S. Cellular deficiency of Werner syndrome protein or RECQ1 promotes genotoxic potential of hydroquinone and benzo[a]pyrene exposure. Int $\mathrm{J}$ Toxicol. 2014; 33: 373-81.

48. Galvan N, Lim S, Zmugg S, Smith MT, Zhang L. Depletion of WRN enhances DNA damage in HeLa cells exposed to the benzene metabolite, hydroquinone. Mutat Res. 2008; 649: 54-61.
49. Ren X, Lim S, Smith MT, Zhang L. Werner syndrome protein, WRN, protects cells from DNA damage induced by the benzene metabolite hydroquinone. Toxicol Sci. 2009; 107: 367-75.

50. Winn LM. Homologous recombination initiated by benzene metabolites: a potential role of oxidative stress. Toxicol Sci. 2003; 72: 143-9.

51. Wilson DM, 3rd, Bohr VA. The mechanics of base excision repair, and its relationship to aging and disease. DNA Repair (Amst). 2007; 6: 544-59.

52. Baynton K, Otterlei M, Bjoras M, von Kobbe C, Bohr VA, Seeberg E. WRN interacts physically and functionally with the recombination mediator protein RAD52. J Biol Chem. 2003; 278: 36476-86.

53. Keller A, Nesvizhskii AI, Kolker E, Aebersold R. Empirical statistical model to estimate the accuracy of peptide identifications made by MS/MS and database search. Anal Chem. 2002; 74: 5383-92.

54. Nesvizhskii AI, Keller A, Kolker E, Aebersold R. A statistical model for identifying proteins by tandem mass spectrometry. Anal Chem. 2003; 75: 4646-58.

55. Vichai V, Kirtikara K. Sulforhodamine B colorimetric assay for cytotoxicity screening. Nat Protoc. 2006; 1: 1112-6.

56. Kitano K. Structural mechanisms of human RecQ helicases WRN and BLM. Front Genet. 2014; 5: 366. 